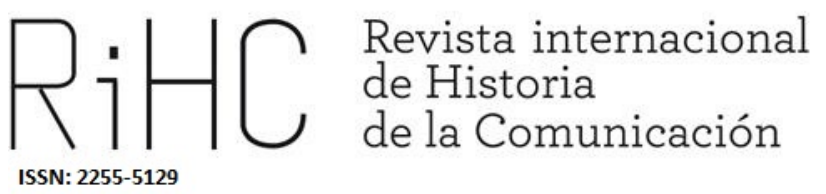

\title{
DE SANTANDER A LA \\ REPÚBLICA MEXICANA: EMILIO \\ REY, SOLDADO, ESCRITOR Y \\ PERIODISTA DE MÉXICO
}

From Santader to Mexican Republic: Emilio Rey, soldier, writer and journalism of Mexico

DOI: http://dx.doi.org/10.12795/RiHC.2019.i12.13

Recibido: 06/03/20019

Aceptado: $11 / 06 / 2019$

Publicado: $15 / 06 / 2019$

Fernández Arriola Autor

Universidad Veracruzana. Xalapa, Veracruz, México

afernandez@uv.mx

ORCID (iD) 0000-0002-8671-7197 
Resumen: Escritor de dos mundos, el polígrafo Emilio Rey (1827-1871) fue hijo de una familia francesa radicada en Santander, donde nació y vivió hasta cerca de su adolescencia; luego, y por razones aún desconocidas, viajó a la joven República Mexicana, en donde se naturalizó, luchó como soldado mexicano, formó una familia, incursionó inclusive en la vida política y escribió toda su obra literaria, a la sombra de un romanticismo asumido en persona y en obra. Debido a esta dualidad, denominada "Nepantla» por Arturo Souto Alabarce, Rey no ha sido considerado hasta ahora como hombre de letras cantábricas ni como un escritor netamente mexicano. En estas páginas se revisará su actuación dentro de las instituciones culturales y públicas de México, y se le ubicará en el contexto de la vida social y política, desde donde se analizarán sus vaivenes ideológicos, sus múltiples vacilaciones, así como sus definitivos aportes estéticos. Adentrado en una literatura de emergencia, en los límites de esta doble identidad, nos enfocaremos, sobre todo, a la revisión de su papel como periodista, promotor y autor de un grupo de poemas, una comedia, llevada con éxito a la escena, y como el creador de una novela que no ha tenido repercusión en las letras mexicanas por haber sido publicada por entregas en un periódico de vida efímera.

Palabras clave: Emilio Rey, República Mexicana, EI Siglo XIX, Poesía, La Balanza de Astrea.

\begin{abstract}
A writer of two worlds, the polygraph Emilio Rey (1827-1871) was son of a French family that lived in Santander, his birthplace and home until his adolescence; but later, and for unknown reasons, he traveled to the then young Mexican Republic, where he was naturalized and fought as a Mexican soldier, he formed a family, made incursions into political life and wrote all of its literary works, in the shadow of an assumed romanticism in person and work. Due to this duality, denominated "Nepantla» by Arturo Souto Alabarce, Rey has not been considered until now as a man of cantabrian letters nor as a Mexican writer. In these pages, his actions inside cultural and public institutions will be analyzed, and he will be situated in the social and political context, where his ideological swings will be studied, as well as his multiple vacillations, and his aesthetic contributions. Inside an emerging literature, in the limits of this double identity, we will focus, specially, in the revision of his job as journalist, promotor, author of a group of poems, a comedy, which was taken into a successful play, and as a creator of a novel that has had no repercussion in Mexican letters since it was published in episodes in a short-life newspaper.
\end{abstract}

Keywords: Emilio Rey, Mexican Republic, EI Siglo XIX, Poetry, La Balanza de Astrea.

\title{
Introducción
}

El propósito de estas páginas sobre el olvidado escritor santanderino Emilio Rey, inmigrado a México desde su primera juventud, será, en primer término, restituirlo para las letras mexicanas, ya que desde el último tercio del siglo XIX y hasta nuestros días no ha sido valorado por la crítica, para bien o para mal, ni en su país de origen ni en el nuestro, que fue el de adopción y donde se formó y compuso sus obras. A Rey se le ha ignorado en los trabajos de carácter histórico sobre la inmigración española y, en sentido 
estricto, hasta ahora no se le ha sido incorporado a las letras mexicanas. Rey no fue considerado en la clásica investigación de Moisés González Navarro Los extranjeros en México y los mexicanos en el extranjero 1821-1970; de igual forma, no fue estudiado en el volumen Españoles en el periodismo mexicano, siglos XIX y XX, donde se compilaron capítulos sobre impresores, periodistas y escritores arraigados en México como Rafael de Rafael, Niceto de Zamacois, Anselmo de la Portilla, Adolfo Llanos y Alcaraz, Telésforo García, Enrique de Olavarría y Ferrari o Santiago Ballescá. Rey tampoco fue incluido en Cántabros del siglo XIX. Semblanzas biográficas, volumen preparado por Mario Crespo López, donde fueron estudiados los emigrantes Anselmo de la Portilla y Casimiro del Collado. Este trabajo se limitará, en forma sucinta, a revisar las acciones, las obras literarias y la actuación militar de Emilio Rey en México y deberá recordarse, en todo momento, que el polígrafo llegó muy joven al país, en donde se formó, quizá en forma autodidacta, como poeta, escritor, periodista, militar y político, es decir, que no fue un intelectual inmigrado sino un emigrante formado en la actividad intelectual en su patria de destino.

\section{Apuntes bibliográficos}

En su “Declaración de contrayente", Emilio Rey afirmó, el 13 de noviembre de 1849, "ser soltero de veinticuatro años de edad", originario "de la Provincia de Santander" y vecino de la Ciudad de México desde hacía "ocho años", o sea, desde 1841. Manifestó además ser hijo legítimo de Juan Bautista Rey y de Catalina Salmón, tener su domicilio en la Tercera Calle de San Francisco desde hacía "un mes"; con anterioridad, "en la [de] Encarnación y Puente de San Francisco, y antes en España" ("Información matrimonial número 98", 1849: ff. 7 y ss.). Iba a cumplir entonces, en realidad, 22 años (no los 24 que declaró), pues había nacido en Santander, el 28 de diciembre de 1827. En su "Partida de bautizo" se había registrado a "doña Rosa Monel" como su madre legítima (suplantada ahora por Catalina Salmón). Transcribo este documento:

A veintinueve de diciembre de mil ochocientos veintisiete, yo don Juan de la Serna, prebendado y cura párroco de la Santa Iglesia Catedral de Santander, bauticé solemnemente en ella y ungí con los santos óleo y crisma a Inocencio [Pedro, entre líneas] Emilio, que nació el día anterior, hijo legítimo de don Juan Bautista Rey y de doña Rosa Monel, naturales de Trie[-sur-Baïse], en Francia, y residentes en esta ciudad. Nieto paterno de don Juan Bautista Rey y de doña Francisca Barbat, vecinos que fueron de Trie[-sur-Baïse]; materno, de don Emilio Monel y doña Dominica Tardos, vecinos del mismo pueblo. Fueron sus padrinos y le cubrieron ambos en el acto del bautismo don Pedro Ruiz Eguilaz y doña Francisca Barbat, a 
quienes advertí el parentesco espiritual y su obligación. Para que conste lo firmo.Pedro, interlineado, vale.- Don Juan de la Serna [rúbrica] (1827: f. 164 v.)

Como puede apreciarse, sus padres eran de ascendencia francesa pero inmigrantes y radicados en la capital cantábrica; el futuro escritor emigró a la República Mexicana, hasta donde llegó para residir en forma definitiva: arribó siendo niño al puerto de Tampico, y se trasladó a la Ciudad de México siendo un adolescente de catorce años de edad, como declaró ante el cura Ignacio Velázquez de la Cadena en la citada "Información matrimonial".

Ignoramos los motivos de su traslado a México. En su poema "Santander", dedicado a su padre, indicó: “¿Por qué quiso la suerte en saña fiera / romper en mi niñez lazos eternos?" $Y$, más adelante, acaso vislumbró como causa eficiente de su emigración la orfandad materna: "Allí arrulla la tumba de mi madre / el mar sonoro al azotar la arena" (La lberia, 18-11-1868: p. 2). Como he dicho en otro lugar", en el "Prólogo" a sus Poesías justificó su inclusión en las letras mexicanas: "Desde niño sentí una grande afición a la poesía, y muy joven aún comencé a escribir versos, inspirado por las suaves brisas del risueño Pánuco" (Rey, Poesías, 1868: p. 3); se refería, entre otros textos, al himno titulado "Tampico", en donde reiteró, en forma temprana, su agradecimiento a la población que le había brindado hospitalidad: "Del azulado Pánuco las cándidas ondinas, / las náyades divinas del dulce Tamesí, / saliendo de sus lechos, en cantos sonorosos / mis versos cariñosos os hagan siempre oír" (1868: p. 189).

El hecho de haber llegado a formar parte de la Asociación Laterana, establecida el 12 de julio de 1868 por algunos de los egresados del antiguo Colegio de San Juan de Letrán, podría dar una pista acerca de la formación escolar de nuestro escritor. El discurso oficial de apertura corrió a cargo del socio Lauro Tagle y ofrecieron los brindis Guillermo Prieto, el propio Emilio Rey, Ignacio Ramírez, Ignacio Manuel Altamirano, José M. Iturbe, Justo Sierra, Manuel de Olaguíbel, Juan Govantes y Manuel Prieto (“Asociación Laterana”, La Iberia, 15-7-1868: p. 3).

El año 1849 fue uno de los más importantes de su existencia. Rey trató en vano de hacerse funcionario público; pero en cambio se empleó como contador en la iniciativa privada; publicó sus primeros poemas conocidos y celebró en la Ciudad de México su matrimonio eclesiástico. Tiempo después -en forma peculiar, cuyas circunstancias ignoramos- se daría de alta como militar de grado en el Ejército Nacional. Un tío de su prometida, el licenciado José Ignacio Pavón, quien ostentaba el cargo de director general de la Aduana Marítima, seguramente intercedió en favor del poeta para que el ministro de Hacienda le diera el nombramiento como "vista de la aduana marítima de

\footnotetext{
${ }^{1}$ En el Cuarto Congreso Prensa y Literatura, organizado en 2018 por El Colegio de San Luis leí la ponencia "Puesta en escena, edición y repercusión en la prensa de la comedia Álgebra del corazón". Estimo pertinente advertir al lector de este trabajo que es posible haya repetida alguna información en ambos textos.
} 
Matamoros", con "el sueldo de tres mil pesos anuales" ("Jalisco", El Siglo XIX, 12-4-1849: p. 408). Hubo a este propósito mucha oposición de la parte «mexicana», inclusive fue hecha pública en la prensa, desde donde se le denostó, y al final se le impidió tomar en firme este cargo ("Suceso notable en el gabinete", El Siglo XIX, 27-4-1849: p. 468). Este primer fracaso dentro de la función pública dio pauta a su vida, llena de altibajos y vaivenes.

Si atendemos a lo asentado en la ya referida "Información matrimonial", Rey era, en el momento de formalizar su relación con Guadalupe Unanue Pavón, el administrador de la Imprenta de Ignacio Cumplido, una de las más importantes del país (f. 7). Fue precisamente en una de las publicaciones producidas en sus talleres, en El Álbum Mexicano, donde había hecho su debut como poeta y divulgó algunas de sus piezas en verso más antiguas: "A Zayda" (t. II, 1849: p. 293), “iVirgen, ten piedad de mí!" (t. II, 1849: p. 352), “Flores de Himeneo" (t. II, 1849: p. 398), "Las gracias de Zaida” (t. II, 1849: p. 416), "Huejutla" (t. II, 1849: p. 439), “Anacreóntica" ("Pura cual de la noche...") [t. II, 1849: p. 470] y "La Viga" (t. II, 1849: p. 543). Emilio y Guadalupe formalizaron su matrimonio durante el mes de noviembre y el 12 de diciembre celebraron su enlace in facie eclesiæe en la Capilla de las Ánimas de la Catedral Metropolitana de México. Los casó el bachiller don Manuel Moreno y Jove, canónigo arcediano. Guadalupe era doncella de 19 años, "natural y vecina de esta Ciudad, hija legítima de don Pedro Unanue y de doña María Isaac Pavón, siendo testigos el bachiller don Bernardo de Mendoza y don José Ignacio Padilla" ("Partida de matrimonio número 244”, 12-12-1849: ff. 84 r.-84 v.)

El matrimonio procreó cuatro hijos. Fue el primogénito Emilio Clemente José Pedro Federico Domingo Juan Nepomuceno Estanislao Pascual Ramón Juan Bautista Juan de la Cruz del Corazón de Jesús, nacido en la capital el 23 de noviembre de 1852 (Libro de bautismos número 39, serie $B$, partida núm. 1,109, f. 134 r.). Moriría antes de alcanzar la adolescencia. Su padre le compuso este epitafio: "Fue el amor de sus padres y el consuelo: / hoy su ángel titular es en el cielo" ("En el sepulcro de mi adorado hijo Emilio", Poesías, 1868: p. 392). En el poema "En mi cumpleaños", fechado el 28 de diciembre de 1866, insistió sobre su pérdida: "iYo le vi morir! Sus ojos / yo los cerré blandamente; / yo deposité en su frente / mi último beso de amor" (Poesías, 1868: p. 369).

Su segundo hijo murió al nacer. En el poema "En la muerte de mi hijo", fechado el 19 de enero de 1855, se quejó ante Dios: "En el silencio de mi triste alcoba, / a la luz de la cera, / tendido miro al niño que me roba / tu poderosa mano justiciera" (1868: p. 311). El 21 de noviembre de 1856 nació su primera hija, bautizada en la Parroquia de la Asunción de la Catedral como María Guadalupe Catarina Brígida Ignacia Federica Juana Nepomucena Francisca de Paula del Corazón de Jesús (Libro de bautismos número 43, serie $B$, partida núm. 1,303, f. 130 r.) Su segunda hija nació en la Ciudad de México, el 28 de marzo de 1863 y fue bautizada en la misma Parroquia el día 31, con los nombres 
de María de los Dolores Piedad Tomasa Rosa Josefa Rita de Casia Francisca de Paula del Corazón de Jesús (Libro de bautismos número 50, serie B, partida núm. 379, f. 31 r.)².

Su vida matrimonial resultó tan fluctuante como la propia circunstancia de sus facetas más controvertidas: su vida pública, mercantil e institucional, así como su actuación en el campo del periodismo y la literatura; y, por otra parte, su carrera como militar y político, la cual siguió la suerte de la compleja inestabilidad del Estado nacional en consolidación; en la carrera de las armas alcanzó el grado de Coronel de Caballería, y a título póstumo el de general del Ejército.

\section{Sus primeras incursiones literarias}

En el campo literario y la esfera de lo institucional, Rey se asoció desde muy joven a diversas corporaciones artísticas y culturales. Tomó parte en los trabajos de la Academia Literaria de San Juan de Letrán, en donde se le admitió como miembro a los 22 años de edad, cuando se presentó como aspirante y dio lectura en forma protocolaria al poema "Gloria" (El Demócrata, 16-6-1850: p. 3; y EI Siglo XIX, 17-6-1850: p. 675). En la compilación de sus Poesías, esta pieza apareció con la dedicatoria: "A mis hermanos de Letrán" (1868: pp. 69-70). Esta "hermandad» nos autoriza a suponerlo como integrante de alguna de las logias masónicas y esta hipótesis puede sustentarse, al mismo tiempo, con el contenido del poema "Lazo doble", especie de colofón y despedida del volumen Poesías, dedicado al maestro Ignacio Manuel Altamirano, impulsor de dicha "hermandad»: "Y en esta de mi Libro / última hoja, / Libro que encierra tantas / tiernas memorias, / traza mi mano / con firmes caracteres: / Altamirano" (1868: p. 400). Como ahora se sabe, Altamirano encabezó el programa cultural de la fundación de la literatura mexicana con posterioridad al periodo de la República Restaurada, al organizar las Veladas Literarias, efectuadas durante los años 1867 y el siguiente; al dirigir El Renacimiento. Periódico literario durante 1869; al fundar, el 5 de mayo de 1870, El Libre

\footnotetext{
${ }^{2}$ Cuando Rey tomaba parte en la milicia y la política, durante las incidencias de las Guerras de Reforma e Intervención, y radicó en distintas plazas del interior, su esposa Guadalupe Unanue Pavón, quien había permanecido en la Ciudad de México, procreaba una hija fuera del matrimonio con el señor Gabriel Moreno Salazar. Aurelia Gabriela Guadalupe Agustina Alberta Moreno Unanue nació el 7 de abril de 1861 y fue bautizada como hija legítima en la Parroquia de San Sebastián (Libro número 30 de bautismos, partida núm. 136, f. 142 r.) Unos meses después de la muerte de Rey, su viuda contrajo matrimonio eclesiástico con el mencionado señor Moreno Salazar, de quien enviudaría por segunda vez ("Información matrimonial de don Gabriel Moreno Salazar y Guadalupe Unanue viuda de Rey" [1872] en Información matrimonial, legajo núm. 23, sin foliatura, 24 / II. Archivo de la Parroquia de la Asunción del Sagrario Metropolitano de México). El 3 de mayo de 1884, Aurelia contrajo matrimonio eclesiástico con Lauro María Ceballos Ceballos, en la Parroquia de la Asunción del Sagrario Metropolitano de México (Libro número 29 de matrimonios, partida núm. 51, ff. 87 v.-88 r.)
} 
Pensador. Periódico político, filosófico, literario, y al proponer la reapertura del Liceo Hidalgo.

Rey participó en 1850 como invitado en la función del primer aniversario del Liceo Hidalgo, en donde leyó su poema "El porvenir", aún sin ser socio de esta agrupación. El texto apareció en su lección definitiva con la siguiente nota: "Esta composición fue leída por su autor en la sesión pública que el Liceo Hidalgo tuvo en celebridad de su primer aniversario el día 15 de septiembre de 1850" (Poesías, 1868: pp. 99-101). A esta ceremonia, realizada en el Palacio de Minería, acudió como invitado de honor el Presidente de la República; Rey estuvo acompañado por Francisco Granados Maldonado, quien dio lectura a su "Himno a Hidalgo" (EI Siglo XIX, 15-9-1850: p. 1.014), y por su contemporáneo Marcos Arróniz, quien declamó en esta ceremonia su poema “La inspiración" (La llustración Mexicana, t. II, 1851: pp. 207-208).

Poco después, Rey intervino en "la solemne distribución de premios del nacional y primitivo Colegio de San Juan de Letrán en la noche del 10 de noviembre de 1850", en donde declamó el poema "Ciencia y gloria" (EI Siglo XIX, 22-11-1850: p. 2; compilado en Poesías, 1868: pp. 89-91). Pronto sería invitado como socio titular del Liceo Hidalgo. Presentó su candidatura a los titulares de ese organismo y dio lectura al poema "La Alhambra de Granada. (Oriental)", con el que fue admitido en la corporación (Presente Amistoso Dedicado a las Señoritas Mexicanas, 1851: pp. 281-283). También fue admitido como socio de la Compañía Lancasteriana de México; el aspirante contestó la aceptación del nombramiento, tratada en la sesión del 21 de abril de 1851; en esta Compañía llegó a desempeñarse como prosecretario ("Remitido", El Siglo XIX, 9-7-1851: p. 2; y Diccionario Universal de Historia y Geografía, t. II, 1853: pp. 467-472). Muchos años después, el 18 de enero de 1857, leería su poema "A la virtud", en la ceremonia inaugural del Liceo Mexicano (Rey, Poesías, 1868: pp. 121-127).

Rey supo allegarse al seno de las instituciones culturales y al ámbito de la esfera pública, actividades que intercaló con su incursión en el ramo mercantil: fundó y mantuvo por breve tiempo, a partir de junio de 1851, la "Librería de La Sinceridad", Calle de Donceles número 4, en donde además de vender libros de religión, ciencias, literatura "y algunas selectas piezas de música", ofrecía servicios como comisionista e importador de productos, así como de la impresión de papelería ("tarjetas de visita y convites, libranzas, conocimientos, etcétera, a precios muy moderados"); contaba además con taller de encuadernación y la venta de papelería y mercería "del mejor gusto" ("Librería de La Sinceridad", El Universal, 5-7-1851: p. 4).

Esta empresa mantuvo relación con el proyecto de la edición del periódico La Sinceridad, impreso de ocho páginas producido por la Imprenta de Juan R. Navarro, a cargo de Leandro J. Valdés; era bisemanal y aparecieron 35 números, entre el 2 de abril y el 30 de julio de 1851; el subtítulo reflejaba el contenido del papel: Periódico de política, literatura y comercio. Rey publicó allí algunos epigramas y sus poemas "Fe, esperanza y 
caridad" (2-4-1851: p. 5), "Mirada de amor" (9-4-1851: p. 23), "A mi buen amigo don Tomás Ruiseco" (19-4-1851: p. 46), "Muerte" (30-4-1851: p. 71) y “El beso" (26-7-1851: p. 268), así como el artículo "Modas" (17 / V / 1851: pp. 111-112). Rey estuvo asociado al periódico, aunque únicamente era propietario de la "Librería de La Sinceridad" ("Al comercio", EI Siglo XIX, 26-10-1851: p. 4).

Rey continuaba con su ingente actividad en todos los órdenes: el domingo 16 de noviembre de 1851 compartiría sitio principal con Guillermo Prieto en la distribución anual de premios organizada por el Colegio de Minería, donde dio lectura a uno de sus poemas ("Premios", La Voz de la Religión, 22-11-1851: pp. 670-671). Ignacio Cumplido, por su parte, insertó en su periódico EI Siglo XIX este aviso de suma importancia para nuestro personaje:

Habiéndose separado del escritorio de mi establecimiento don Emilio Rey y emprendido por su parte negocios relativos a los ramos de imprenta y librería, girará solo por sí, sin que sus cuentas tengan relación con las mías, ni yo responsabilidad de ninguna clase respecto de las suyas. ("[Aviso]", 31-12-1851: p. 4).

A pesar de lo dicho, Rey siguió publicando sus obras en los periódicos impresos por Cumplido; en La Ilustración Mexicana se estamparon los poemas "La religión" y "Goliath" ([1851]: p. 120); y el titulado “A La Habana” ([¿1851?]: pp. 391-392); en la tercera edición del Presente Amistoso Dedicado a las Señoritas Mexicanas, otro de los papeles producidos por este impresor, aparecieron los poemas "La cautiva. (Leonor)" [1851: pp. 354-359], “Flores marchitas" (1851: p. 408); “La Magdalena” (p. 422), “Belleza y sentimiento" (pp. 74-77), "Desengaño. (Josefa)" [pp. 197-200]; el ya mencionado "La Alhambra de Granada. (Oriental)" [pp. 281-183] y la prosa “Margarita" (pp. 411-416).

En ese mismo tiempo se informó en El Monitor Republicano la aparición -“muy próximamente"- de su primer tomo de Poesías ("Gacetilla de la Capital", El Monitor Republicano, 21-7-1851: p. 4); se trataba de su cuaderno Recuerdos de Anáhuac. Colección de cantos históricos mexicanos, aparecido sin año de edición pero con la dedicatoria a José Fernando Ramírez fechada en julio de 1852. Sus poemas de carácter testimonial fueron novedosos en el proceso de recuperación de la historia remota de México, y se adelantó en la elaboración de estos temas a Las aztecas de José Joaquín Pesado (1854: 60 pp.) y, entre otras obras, a las Leyendas mexicanas de José María Roa Bárcena (1862: pp. 11-256).

El santanderino participó en la "Apoteosis" en honor del comediógrafo desaparecido Manuel Eduardo de Gorostiza, organizada el mes de diciembre de 1851 por los empresarios teatrales Mosso Hermanos, de la capital de la República, en donde declamó el poema que comienza "iÁngel del entusiasmo...!" (El Universal, 2-1-1852: p. 3). 


\section{De Coronel a Secretario de Gobierno}

Su papel como militar cobró cierta notoriedad en las incidencias de la Revolución de Ayutla, al haberse levantado en armas en defensa del dictador general don Antonio López de Santa Anna. Y mientras éste partía al exilio desde el puerto de Veracruz, las tropas de Rey salieron en desbandada y se refugiaron en el norte de la República. En EI Saltillo fueron derrotadas. Pese a esto, a Rey se le restituyó el grado de Capitán de Caballería permanente y se le revalidó el grado de Comandante de Escuadrón, grados que le habían sido conferidos por el general López de Santa Anna ("Ministerio de Guerra y Marina", El Siglo XIX, 9-4-1856: p. 2).

Poco después se le designó "Comandante de Escuadrón veterano" y se le "ascendió a Teniente Coronel de Caballería permanente, colocándolo como Comandante del Escuadrón Activo de Lanceros de Jalisco" ("Despachos expedidos por el excelentísimo presidente sustituto, desde el 16 del corriente hasta el 22 del mismo", Diario Oficial del Supremo Gobierno de la República Mexicana, t. I, 3-10-1856: p. 1).

De allí pasó a la Jefatura política de Lagos [hoy de Moreno], Estado de Jalisco, en donde también ocupó la Comandancia militar del Cantón. El 31 de diciembre de 1857, Rey comunicó al general Anastasio Parrodi, entonces gobernador de Jalisco, sobre "las sospechas que se tenían de que, en las altas regiones de la administración pública se fraguaba una nueva evolución política" ("Resumen de los acontecimientos", La Sociedad, 22-1-1858: p. 1); el estado de cosas obligó a Rey a preparar, desde su plaza, un documento en donde denunció la posibilidad de un levantamiento en armas por parte de las fuerzas enemigas ("Acta de San Juan de los Lagos", El Siglo XIX, 13-1-1858: p. 2) y poco después lo manifestó ante la opinión pública ("Proclama de Emilio Rey", El Siglo XIX, 20-1-1858: p. 3). En resumidas cuentas, Rey se pronunció contra las «Bases de Tacubaya» y lanzó "un manifiesto a la nación, protestando, en prosa", todo lo cual le acarrearía un cautiverio en la Prisión de Santiago Tlatelolco, en la Ciudad de México (“"Notas sueltas». iTambién él!", La Sociedad, 9-1-1858: p. 3); allí arregló sus poemas “El pensamiento" (Poesías, 1868: pp. 327-329), “A la luna. En mi prisión” (pp. 330-331) y "Dolor" (pp. 332-333).

Al recobrar la libertad, de nueva cuenta se enroló en el movimiento liberal. El 16 de abril de 1860, Rey participó en la entrega del gobierno del Estado de Tamaulipas al gobernador constitucionalista Juan José de la Garza ("Tampico", La Sociedad, 10-5-1860: p. 3). En junio, Rey "Ilegó a Veracruz, procedente de Tampico, en el Indianola" ("Don Emilio Rey", La Sociedad, 27-6-1860: p. 2). Casi de inmediato, aceptó una misión diplomática a Madrid, encomendada por Benito Juárez ("Emilio Rey", La Sociedad, 5-81860: p. 3). En esta ciudad, compuso el soneto "Padilla, 1521" (Poesías, 1868: p. 337); en París, el poema "A Mlle. de R.***” (p. 338); arregló el titulado "A Nápoles", en esta ciudad (p. 339) y, en la travesía de regreso a América, escribió "En el mar", donde 
dispuso esta nota: "A bordo del paquete inglés Oneyda navegando de Southampton a Santhomás. Diciembre de 1860" (pp. 340-341).

En la primavera de 1861, Rey solicitó al Ejército una licencia de dos meses, "para pasar a San Luis" ("El coronel don Emilio Rey”, El Siglo XIX, 28-3-1861: p. 3). En julio, Rey ya despachaba allí como secretario de gobierno interino, cuyo titular en el ejecutivo era el militar Sóstenes Escandón ("San Luis Potosí", El Siglo XIX, 21-7-1861: p. 4). El escritor firmó el decreto relativo a los Tribunales Especiales y otros ocursos de carácter oficial (“Noticias sueltas", La Unidad Católica, 22-7-1861: p. 3).

El 6 de septiembre, Rey escribió desde San Felipe al ministro de la Guerra, don Santos Degollado, para informarle que tanto el Tercer Batallón de Caballería como el Escuadrón de Gendarmes habían defeccionado, "de manera que en San Luis Potosí sólo quedaban quinientos hombres del Batallón de Seguridad Pública por toda guarnición"; por tanto, le pedía enviara refuerzos para la plaza ("Ministerio de Guerra y Marina", El Siglo XIX, 14-9-1861: p. 3). Ya como titular de la Secretaría de Gobierno, Rey fue designado gobernador suplente, mientras el titular Escandón salía a "perseguir a Márquez y a Heras, que se habían vuelto a presentar en algunas poblaciones del mismo Estado" (“Noticias sueltas”, La Unidad Católica, 5-111861: p. 3).

En diciembre, Rey se encontraba en la Ciudad de México, desde donde salió "con una brigada de Caballería para perseguir a los bandidos que infestaban el camino de la capital a Arroyo Zarco". Esta acción tuvo el propósito de "restablecer el servicio regular de correo" ("El señor don Emilio Rey", La Unidad Católica, 13-12-1861: p. 3). El coronel Rey situó a su brigada en Tepeji del Río, desde donde se realizaban los recorridos de vigilancia ("Tepeji del Río", La Unidad Católica, 23-12-1861: p. 2).

En enero de 1862, Rey se trasladó Ixmiquilpam, hoy Estado de Hidalgo, para seguir asediando y persiguiendo "a los restos de las gavillas reaccionarias". Llevaba la instrucción de trabajar en forma combinada "con el general Carbajal" ("Noticias nacionales", El Siglo XIX, 22-1-1862: p. 3). La consigna era pacificar a los indígenas de Orizavita y devolverlos "pronto al orden" ("Noticias nacionales. Ixmiquilpam", El Siglo $X I X, 2-2-1862:$ p. 3).

Por desgracia, el coronel Rey sufriría "un descalabro» en San Juan del Río, a causa de la "poca vigilancia" observada por sus tropas. Rey fue "destituido del mando de la brigada que estaba a sus órdenes" (" "Noticias nacionales». Descalabro", El Siglo XIX, 16-2-1862: p. 4); y se le sujetó a juicio (“El señor don Emilio Rey”, El Constitucional, 20-2-1862: p. 3). En abril, el general Anastasio Parrodi restituyó al coronel Emilio Rey en sus funciones castrenses y le otorgó la elevada comisión de Jefe del Estado Mayor ("Noticias nacionales", El Siglo XIX, 27-4-1862: p. 4). 


\section{Vuelta a la vida civil y al periodismo}

Poco después, Rey solicitó licencia al Ejército y pasó a la vida civil, y ya reinstalado en la Ciudad de México retomó sus actividades periodísticas. Comenzó a colaborar en el periódico El Independiente, en donde escribió, entre otros asuntos, algunos artículos en contra del ministro de la Guerra. A Rey se le apresó y confinó por delitos de guerra y no por difamación, en su calidad de periodista. En la sesión del 9 de marzo de 1863, el Congreso recibió y debatió en el pleno sobre una solicitud de Emilio Rey, mediante la cual pedía amparo "contra la arbitrariedad del C. ministro de la Guerra que lo redujo a prisión". El diputado Ignacio Ramírez lo apoyó. En su defensa dijo que el ministro abusaba "de sus facultades extraordinarias" e imploraba "la protección de los ciudadanos diputados en favor del coronel Emilio Rey y otras personas". Ramírez argumentó: Rey se había separado "del servicio militar" y desde el ámbito civil había hecho públicas sus "opiniones liberales y reformistas"; señaló también que el ciudadano Rey estaba "protegido por la Constitución y por otras leyes vigentes"; y que era "hábil militar y hábil escritor". Ramírez propuso al Congreso que Rey fuera juzgado por las autoridades civiles y no por la corte marcial; pero el Congreso denegó esta proposición (“Sesión del 9 de marzo de 1863", Diario de los debates, 1873: pp. 192-193).

El móvil de la prisión de Rey tenía una razón por partida doble: el periodista renegaba de que se le hubiera confiado "la dirección de la guerra a personas que nada dirigen" y, además, postulaba desde las páginas del primer número del periódico El Independiente al general Parrodi para sustituir al ministro ineficaz e inútil. Ante la proposición de Rey, el general Parrodi se deslindó de inmediato, en carta fechada en México, el 2 de marzo de 1863:

No obstante el deseo que manifesté a usted de que no se ocupara de mi individuo en El Independiente, me ha postulado en su primer número, para desempeñar la cartera de Guerra, sin atender a mis indicaciones; pero ya que usted lo hizo, le reitero lo que tantas veces hemos hablado: mi única aspiración es defender la independencia de la República, por la que ya he derramado mi sangre en Padierna, o separarme del servicio militar, llegada la oportunidad de que pueda hacerlo con honor (“El señor general Parrodi”, EI Siglo XIX, 3-3-1863: p. 4).

La protección brindada a Rey por el general Parrodi fue decisiva para su futuro dentro de la milicia y la política. Cuando Parrodi dio el vuelco y se pasó al lado de la reacción, obligado por las circunstancias, Rey lo siguió en forma disciplinada. Por esta razón, el coronel Rey sirvió un tiempo al gobierno Imperial de Maximiliano; en 1866 despachaba en la Ciudad de México y tenía el cargo de jefe de la Primera División de Infantería, Caballería y Gendarmería (Almanaque imperial, 1866: p. 104). Naturalmente, se le tachó de apóstata del liberalismo y del "Juarismo». Concluido el periodo del segundo Imperio, Rey abandonó la milicia y retornó a la vida periodística y literaria. En 1868, publicó su tomo de Poesías, en cuya "Introducción" señaló: "Varias de mis producciones se han 
perdido con los periódicos en que salieron a la luz, y muchas otras que guardaba inéditas en mis cartones, se han extraviado en diversas épocas, en los continuos vaivenes de mi azarosa vida de soldado" (Poesías, 1868: p. 3).

Mientras se hallaba también alejado de política retornó a sus labores de escritor. Publicó en el periódico Don Simón, de Fresnillo, Zacatecas, sus poemas "Amar es vivir" (17-11869: p. 3) y “Dudas" (21-2-1869: p. 3). Colaboró en diversos periódicos de la Ciudad de México; publicó su poema "AI tabaco" en EI Siglo XIX (27-2-1870: pp. 2-3); y además compuso la comedia Álgebra del corazón, en dos actos y en verso, montada en 1870 por la Compañía del Teatro Nacional, dirigida por Eduardo González; esta pieza se estrenó el domingo 24 de abril, con éxito de taquilla (Altamirano, "Revista de la Semana", El Siglo XIX, 24-4-1870: p. 2). Concepción Méndez hizo el papel de Concha; María de Jesús Servín, el de Adela; Luis Martínez hizo el Don Blas y Eduardo González, el poeta Luis (Álgebra del corazón, 1870: p. 31).

Luego del éxito de público tenido con su comedia, creyó que el bienestar económico de su familia podría sostenerse con los productos literarios; anunció la composición de una nueva pieza de teatro -al parecer nunca escrita-y reflexionaba sobre la posibilidad de retomar la escritura de textos narrativos, pues su primera novela, como se ha visto, había pasado desapercibida por la crítica e inclusive por los lectores, al haber aparecido por entregas, en 1853, en las páginas del modesto periódico La Estrella. Periódico semanario de literatura, impreso por los talleres de Boix, Beserer y Compañía, en la capital. El maestro Altamirano, en 1869, la reprodujo igualmente por entregas en EI Renacimiento (t. I, pp. 269-273, 287-288 y 299-304). Asimismo, en aquel entonces dio a la estampa en el semanario liberal El Domingo los poemas "Almas gemelas" (12-3-1871: p. 36), "Lágrimas" (16-4-1871: pp. 83-84) y, en forma póstuma, apareció “Desencanto y consuelos" (22-101871: p. 57).

\section{Ambiciones políticas y tribuna periodística}

Abandonada la milicia, retirado a la vida privada y de regreso a la escritura literaria, en forma paralela reaparecería pronto en su personalidad la picazón de la política, que ahora habría de combinar con el periodismo. Así que participó con la pluma durante la campaña para la Presidencia de la República, en la que habría de reelegirse, una vez más, don Benito Juárez. Competiría el presidente en funciones contra Sebastián Lerdo de Tejada, su antiguo ministro de Gobernación, y Porfirio Díaz, es decir, contra otros dos candidatos igualmente liberales. Rey puso su pluma al servicio de la campaña electoral de Lerdo de Tejada o-como se decía entonces en la prensa- a la facción lerdo-porfirista. 
Al dar comienzo el año electoral, José María Vigil, en su editorial "El año de 1871", aparecido en EI Siglo XIX, advertía a la opinión pública:

las necesidades de la República son bien marcadas, y no será por ignorancia por lo que dejen de satisfacerse. La paz, la libertad y el respeto a la ley es la triple base en que descansará el edificio de nuestro porvenir; afianzarla es la estrecha obligación así de los ciudadanos como de los partidos; destruirla o siquiera conmoverla es el mayor crimen que pueda cometerse, no contra un hombre o contra una bandería, sino contra el pueblo, contra la nación entera" (1-1-1871: p. 1).

Comenzaba la lucha político-electoral. Rey dejó la Redacción del periódico EI Siglo XIX y viajó desde la Ciudad de México rumbo a Zacatecas para dar paso a sus nuevas proyecciones políticas ("“Gacetilla». Don Emilio Rey”, El Monitor Republicano, 10-11871: p. 3). Había viajado ingenuamente de incógnito; en el periódico México y Europa se comentó: "Este conocido y aventajado escritor se encuentra en Zacatecas, adonde, según se dijo, marchó para el arreglo de asuntos particulares. Hay quienes supongan otros motivos al viaje que ha hecho ese señor" ("Gacetilla", México y Europa, 10-1-1871: p. 3).

No se habría de hacer, en forma inmediata, el desvelamiento de sus intenciones ni la identidad del candidato de su preferencia e interés. Su actuación, sin embargo, tendría tintes e influjos regionales. En La Voz de México se comentó: "Han dicho algunos de nuestros colegas que don Emilio Rey es propagador de la candidatura lerdista en San Luis y Zacatecas; otras personas creen que es agente juarista" ("Gacetilla", 8-1-1871: p. 3). En El Monitor Republicano se hizo burla de lo aparecido en La Revista Universal: "Según la buena de la Revista, don Emilio Rey no es agente de don Sebastián, sino que fue a Aguascalientes porque aquel clima le sienta mejor" (" "Gacetilla». Don Emilio Rey", 24-2-1871: p. 4).

El Monitor Republicano, en cuya línea informativa se exaltaban las virtudes del presidente Juárez, tronó contra Rey, pues apostaba que trabajaba a favor de Lerdo de Tejada y contra don Benito. Dijo su redactor: "Ese ex empleado del Ministerio del difunto Maximiliano, va a asomar por fin la oreja, y dar un mentís solemne a aquellos que le pintaron como buscador tan sólo de un buen clima y no de agente de don Sebastián". Luego dio punto final a la idea: "Dios los cría y ellos se juntan. Un ex empleado del Imperio, por convicción; un reaccionario obcecado no puede menos de filiarse bajo la bandera de un don Sebastián" (“"Gacetilla». Don Emilio Rey", 8-3-1871: pp. 3-4). Y reiteraba su sorpresa: ¿cómo podía ser Rey "el cantor de las gracias de don Sebastián, olvidando que éste hizo fusilar a aquél”? ("«Gacetilla». Don Emilio Rey", El Monitor Republicano, 22-3-1871: p. 3). 
Rey fundó como órgano impreso para la campaña el periódico La Balanza de Astrea, que comenzó a circular en marzo. Rey apareció como su redactor y desde el impreso enarboló la candidatura a la Presidencia de Lerdo de Tejada (" "Gacetilla». La Balanza de Astrea”, La Voz de México, 23-3-1871: p. 3). A Rey se le achacó, de igual forma, la especie de ser uno de los redactores del periódico La Jeringa, impreso en Aguascalientes, también de filiación lerdo-porfirista, y "con el exclusivo objeto de insultar a los periodistas que no piensan como la fusión. La calumnia y la injuria es el fin: jamás se pensó en raciocinar", como señaló el redactor de El Monitor Republicano (" "Gacetilla». Don Emilio Rey", 9-4-1871: p. 3).

En este periódico continuó el ataque sistemático contra Emilio Rey y La Balanza de Astrea. El redactor volvió a la carga:

Sentimos que este periódico del apreciable señor Rey, trate tan acremente al señor Juárez. Para nosotros los hijos de México, el actual presidente tiene grandes y eminentes servicios y por eso es que duélenos, y mucho, que en nuestra misma patria sea censurado por personas que han sido en ella tan bien aceptadas, y para las que México tiene franca y leal hospitalidad. (“La Balanza", 19-4-1871: p. 3).

Juvenal, redactor en jefe del Monitor, terminaría lanzando una advertencia a Rey, para procurar cesaran los ataques al ejecutivo y a su periódico:

Sean cuales fueren las opiniones que tenga el señor Rey, no está facultado para herir sin razón y descender al terreno de las personalidades. Creemos que su buen juicio considerará justa esta advertencia, y que desde luego cesará la enfadosa controversia que mantiene en contra de nuestro periódico. ("Boletín del Monitor", El Monitor Republicano, 29-4-1871: p. 1).

\section{Elección y muerte}

Como es notablemente sabido, en la elección presidencial de 1871 Juárez volvió a triunfar, y Emilio Rey, quien como se ha visto fue partidario de Lerdo de Tejada y no de don Benito, resultó no obstante electo diputado propietario por el 18 o distrito de Guanajuato, con cabecera en la población de Iturbide ("Lista de los diputados electos para el Sexto Congreso Constitucional”, El Monitor Republicano, 18-8-1871: p. 1). Toda esta situación, contradictoria a todas luces, descontroló aún a los más enterados en los secretos de la política.

Nuestro personaje, quien por fin iba a alcanzar con este triunfo electoral una posición estable y favorecida con que hacer frente a su familia, no alcanzó a tomar posesión de su curul, pues lo venció una tifoidea galopante. Según Francisco Sosa, el escritor murió 
en torno "al bullicio" desatado por los resultados "de la lucha electoral, y esperando de un momento a otro ver desencadenarse una tempestad política". Su fallecimiento acaeció el 4 de septiembre de 1871, en la capital de la República. Se transcribe su acta de defunción:

[Al margen]: 1,921. / Mil novecientos veintiuno. / Rey, Emilio. [Incontinente]: En la Ciudad de México, a las once y media de la mañana del día cuatro (4) de septiembre de mil ochocientos setenta y uno (1871), ante mí, Joaquín Díaz, juez primero (1을 del Estado Civil, compareció el ciudadano Manuel Antonio Mercado, de Morelia, mayor de edad, casado, abogado, vive [en la] Calle del Correo Mayor número seis (6), y dijo: que hoy a las tres y media (3 1/2) de la mañana, falleció en la calle Cerrada de la Moneda número diez (10), de fiebre perniciosa, el ciudadano Emilio Rey, de España, naturalizado mexicano, de cuarenta y dos (42) años, militar, casado con doña Guadalupe Unanue, de México, mayor de edad; ignora el compare[cie]nte los nombres de los padres del finado. Fueron testigos Gabriel Núñez y Juan Rodríguez, de México, mayores de edad, casados, domésticos, viven el primero [en la] Calle de la Canoa número nueve (9), el segundo en la calle de la Rinconada del Jardín número seis (6), y no son parientes del finado. Con lo que terminó esta acta que ratificaron después que les fue leída, y firmó el que supo; expidiéndose la boleta para nicho al [sic] San Fernando. -Joaquín Díaz.- M. A. Mercado.- Firmado Joaquín Díaz [rúbrica]. (Libro de defunciones de 1871. Juzgado del Registro Civil de la Ciudad de México, acta núm. 1,921, f. 515).

Sosa abundó:

Emilio Rey, el poeta y escritor modesto, el soldado republicano, ha dejado de existir ayer, y creemos un deber sagrado consagrar estas líneas a su memoria.

Nada habrá más triste, que la suerte que ha cabido a nuestro pobre amigo. Después de atravesar por largo tiempo una senda llena de espinas, cuando vislumbraba un descanso, un consuelo y, sobre todo, cuando ya miraba no lejano el día de poder ofrecer a los seres más queridos de su corazón, a sus hijos, un pan menos amargo que el de la desgracia, que tan tenazmente le persiguiera, ha sido arrebatado por la mano de la muerte, y se han tornado hoy en lágrimas, las que ayer fueron sonrisas de esperanza (Sosa, "Emilio Rey", El Siglo XIX, 5-9-1871, p. 3). 


\section{Conclusiones}

La tormenta política anunciada por Sosa, disiparía la noticia de su muerte y lo que vino a continuación en la esfera pública habría de adelantar el olvido de este escritor. Quedan, aún sin leerse ni estudiar, las obras en prosa y verso del escritor.

En su juventud, había compuesto cantares de tema histórico consagrados a los próceres más remotos de la tradición indígena de México. En 1852, adelantándose a todos los poetas de México, publicó un cuaderno con cantares dedicados a los héroes e integrado por cuatro piezas: "Netzahualcóyotl” (rey de Texcoco); "Maxtla" (rey de Coyoacán); al soldado valeroso de los tlaxcaltecas, "Huahuicole", y a la mítica princesa "Papatzin".

La mayor parte de su producción poética exploró diversos temas líricos y reunió en un volumen lo que conservaba a la mano, bajo el título Poesías (1868); Rey había publicado por entregas en 1853 una novelita romántica: iAmor de ángel! Novela original, que como se dijo en otro momento- fue reproducida en las páginas del periódico El Renacimiento (1869); y, hacia el final de su vida, incursionó con cierto éxito en el teatro en verso: escribió y se montó en 1870 la comedia Álgebra del corazón, en dos actos. La repercusión de su libro de versos fue muy relativa, ya que no mereció de parte de la prensa sino algunas reseñas.

Ahora bien, su actuación en la vida pública y militar fue vacilante, intermitente e inclusive contradictoria. Al principio estuvo cerca de la plana mayor del general Santa Anna, abismado por las circunstancias; después trató de permanecer en el bando liberal, aunque en el periodo del Segundo Imperio y la Intervención francesa se afilió a la reacción que en un principio brindó apoyo al emperador Maximiliano. Y hacia el final de su vida, logró revertir este descalabro, provocado en buena medida por mantenerse fiel a su superior en el mando castrense, el general Parrodi; y se sumó a los trabajos políticos en el flanco liberal, pero con una actuación suficientemente ambigua: en la apariencia colaboraba con el Juarismo de la última etapa, aunque en la campaña electoral de 1871 apoyó con su actuación y su pluma a Lerdo de Tejada. Para sorpresa de muchos, al triunfar a la brava el Partido del presidente Juárez, a Rey se le eligió como diputado, lo colocó en el pináculo de la política; pero al morir en forma inoportuna no alcanzó a tomar la protesta de ley como representante popular. Como señaló Sosa en su obituario, a Rey se le empezaba a abrir el camino del éxito cuando lo sorprendió la muerte, a los 44 años de edad. 


\section{Fuentes y referencias bibliográficas}

\section{fuentes}

“Acta de San Juan de los Lagos" en El Siglo XIX, 13-1-1858, p. 2.

"Al comercio" en El Siglo XIX, 26-10-1851, p. 4.

Almanaque imperial para el año de 1866 (1866), Imprenta de J. M. Lara, México, p. 104.

ALTAMIRANO, I. M.: "Revista de la Semana" en EI Siglo XIX, 24-4-1870, p. 2.

ARRÓNIZ, M. “La inspiración” [poema] (1851) en La llustración Mexicana, pp. 207-208.

“Asociación Laterana” en La Iberia, 15-7-1868, p. 3.

“Compañía Lancasteriana de México” en El Siglo XIX, 9-7-1851, p. 660.

CUMPLIDO, Ignacio: “[Aviso]” en El Siglo XIX, 31-12-1851, p. 4.

"Despachos expedidos por el excelentísimo presidente sustituto, desde el 16 del corriente hasta el 22 del mismo" en Diario Oficial del Supremo Gobierno de la República Mexicana, 3-10-1856, p. 1.

Diario de los debates. Tercer Congreso Constitucional de la Unión (1873), t. I, Imprenta de Francisco Díaz de León y Santiago White, pp. 192-193.

Diccionario Universal de Historia y Geografía (1853), t. II, pp. 467-472.

“Don Emilio Rey" en La Sociedad, 27-6-1860, p. 2.

“El coronel don Emilio Rey" en El Siglo XIX, 28-3-1861, p. 3.

“El señor don Emilio Rey" en La Unidad Católica, 13-12-1861, p. 3.

“El señor don Emilio Rey” en El Constitucional, 20-2-1862, p. 3.

“El coronel don Emilio Rey" en El Siglo XIX, 28-3-1861, p. 3.

“El señor general Parrodi" en EI Siglo XIX, 3-3-1863, p. 4.

“Emilio Rey" en La Sociedad, 5-8-1860, p. 3.

“Gacetilla” en México y Europa, México, 10-1-1871, p. 3.

“Gacetilla” en La Voz de México, 18-1-1871, p. 3.

“Gacetilla de la Capital en El Monitor Republicano, 21-7-1851, p. 4.

“"Gacetilla». Don Emilio Rey” en El Monitor Republicano, 10-1-1871, p. 3. 
“"Gacetilla». Don Emilio Rey” en El Monitor Republicano, 24-2-1871, p. 4.

“"Gacetilla». Don Emilio Rey" en El Monitor Republicano, 8-3-1871, pp. 3-4.

“"Gacetilla». Don Emilio Rey" en El Monitor Republicano, 22-3-1871, p. 3).

“"Gacetilla». Don Emilio Rey" en El Monitor Republicano, 9-4-1871, p. 3.

“"Gacetilla». La Balanza de Astrea” en La Voz de México, 23-3-1871, p. 3.

GRANADOS MALDONADO, F.: “Himno a Hidalgo" [poema] en El Siglo XIX, 15-9-1850, p. 1.014.

"Información matrimonial de don Emilio Rey y de doña Guadalupe Unanue" (1849) en Información matrimonial. Fechas varias (años 1849-1926), legajo núm. 98, sin foliatura. Archivo de la Parroquia del Sagrario Metropolitano de México.

"Información matrimonial de don Gabriel Moreno Salazar y Guadalupe Unanue viuda de Rey" (1872) en Información matrimonial, legajo núm. 23, sin foliatura, 24 / II. Archivo de la Parroquia de la Asunción del Sagrario Metropolitano de México.

Juvenal: "Boletín del Monitor" en El Monitor Republicano, 29-4-1871, p. 1.

"La Balanza" en El Monitor Republicano, 19-4-1871, p. 3.

“Librería de la Sinceridad" [anuncio] en El Universal, t. VI, 5-7-1851, p. 4.

Libro de defunciones de 1871. Juzgado del Registro Civil de la Ciudad de México, acta núm. 1,921, f. 515.

"Lista de los diputados electos para el Sexto Congreso Constitucional" en El Monitor Republicano, 18-8-1871, p. 1.

“Ministerio de Guerra y Marina" en El Siglo XIX, 9-4-1856, p. 2.

“Ministerio de Guerra y Marina" en El Siglo XIX, 14-9-1861, p. 3.

"Noticias nacionales" en El Siglo XIX, 22-1-1862, p. 3.

“Noticias nacionales" en El Siglo XIX, 27-4-1862, p. 4.

“«Noticias nacionales». Descalabro" en El Siglo XIX, 16-2-1862, p. 4.

“Noticias nacionales. Ixmiquilpam" en EI Siglo XIX, 2-2-1862, p. 3.

“«Notas sueltas». iTambién él!” en La Sociedad, 9-1-1858, p. 3.

“Noticias sueltas" en La Unidad Católica, 22-7-1861, p. 3.

“Noticias sueltas" en La Unidad Católica, 5-6-1861, p. 3). 
"Partida de bautizo" de Emilio Rey en Libro número 36 de bautismos, f. 164 v. Archivo Diocesano de Santander, España.

"Partida de matrimonio número 244" de Emilio Rey y Guadalupe Unanue (1849) en Libro número 18 de matrimonios, partida núm. 244, ff. 84 r.-84 v. Archivo de la Parroquia de la Asunción del Sagrario Metropolitano de México.

PESADO, José Joaquín: Las aztecas. Poesías tomadas de los antiguos cantares mexicanos (1854), Imprenta de Vicente Segura Argüelles, México, 60 pp.

"Premios" en La Voz de la Religión, t. I, 22-11-1851, pp. 670-671.

“Proclama de Emilio Rey" en El Siglo XIX, 20-1-1858, p. 3.

“Resumen de los acontecimientos" en La Sociedad, 22-1-1858, p. 1.

REY, E.: “A Zayda” [poema] (1849) en El Álbum Mexicano, t. II, p. 293.

---- : “¡Virgen, ten piedad de mí!" [poema] (1849) en El Álbum Mexicano, t. II, p. 352.

---- : “Flores de Himeneo" [poema] (1849) en El Álbum Mexicano, t. II, p. 398.

----- : “Las gracias de Zaida” [poema] (1849) en El Álbum Mexicano, t. II, p. 416.

----- : “Huejutla” [poema] (1849) en El Álbum Mexicano, t. II, p. 439.

---- : “Anacreóntica" ("Pura cual de la noche...") [poema] (1849) en El Álbum Mexicano, t. II, p. 470.

---- : “La Viga” [poema] (1849) en El Álbum Mexicano, t. II, p. 543.

---- : “Gloria” [poema] (1850) en El Demócrata, 16 / VI, p. 3; (1850) en EI Siglo XIX, 17-4-1850, p. 675; y (1868) en Poesías, pp. 69-70.

----- : “El porvenir" [1850] en Poesías, 1868, pp. 99-101.

---- : “Ciencia y gloria” [poema] en EI Siglo XIX, 22-11-1850, p. 1,286.

---- : “La Alhambra de Granada. (Oriental)” [poema] (1851) en Presente Amistoso Dedicado a las Señoritas Mexicanas, pp. 281-283.

---- : “Fe, esperanza y caridad” [poema] (1851) en La Sinceridad, 2-4-1851, p. 5.

---- : “Mirada de amor” [poema] (1851) en La Sinceridad, 9-4-1851, p. 23.

---- : “A mi buen amigo don Tomás Ruiseco” [poema] en La Sinceridad, 19-4-1851, p. 46.

---- : “Muerte” [poema] en La Sinceridad, 30-4-1851, p. 71.

----- : “Modas" [artículo] en La Sinceridad, 17-5-1851, pp. 111-112.

---- : “El beso" [poema] en La Sinceridad, 26-7-1851, p. 268. 
---- : "La religión" y “Goliath" [poemas] (1851) en La Ilustración Mexicana, t. II, p. 120.

---- : “A La Habana” en La llustración Mexicana (¿1851?), pp. 391-392.

----- : “La cautiva. (Leonor)" [poema] (1851) en Presente Amistoso Dedicado a las Señoritas Mexicanas, pp. 354-359.

---- : "Flores marchitas" [poema] (1851) en Presente Amistoso Dedicado a las Señoritas Mexicanas, p. 408.

----- : "Margarita” [prosa] (1851) en Presente Amistoso Dedicado a las Señoritas Mexicanas, pp. 411-416.

---- : "La Magdalena" [poema] (1851) en Presente Amistoso Dedicado a las Señoritas Mexicanas, p. 422.

---- : "Belleza y sentimiento" [poema] (1851) en Presente Amistoso Dedicado a las Señoritas Mexicanas, pp. 74-77.

----- : “Desengaño. (Josefa)” [poema] (1851) en Presente Amistoso Dedicado a las Señoritas Mexicanas, pp. 197-200.

---- : “La Alhambra de Granada. (Oriental)” [poema] (1851) en Presente Amistoso Dedicado a las Señoritas Mexicanas, pp. 181-183.

---- : Recuerdos de Anáhuac. Colección de cantos históricos mexicanos [1852], México, Imprenta de Vicente Segura Argüelles, 23 pp.

----- : "La cita nocturna. Romance" [poema] (1852) en La Semana de las Señoritas Mexicanas, pp. 155-156.

----- : "Influencias. Los dos ángeles" [poema] (1852) en La Semana de las Señoritas Mexicanas, pp. 397-398.

----- : “Ángel del entusiasmo...!" [poema] en El Universal, 2-1-1852, p. 3.

---- : “En un álbum” [poema] en La Estrella, 23-8-1852, p. 2.

---- : iAmor de ángel! Novela original [primera entrega] (1853) en La Estrella, t. I, 7 / II, pp. 5-7; [segunda entrega], 14 / II, pp. 1-3; [tercera entrega], 21 / II, pp. 1-3; [cuarta entrega], 7 / III, pp. 4-5; [quinta entrega], 21 / III, pp. 5-7; [y sexta y última entrega], 28 / III, pp. 1-3.

---- : Álgebra del corazón. Comedia original en dos actos y en verso (1870), Imprenta de Ignacio Cumplido.

ROA BÁRCENA, José María: Leyendas mexicanas, cuentos y baladas del norte de Europa (1862), Librería Mexicana, Agustín Masse, editor, México, pp. 11-256.

---- : "Santander" [poema] en La Iberia, 18-11-1868, p. 2.

---- : Poesías (1868), Tipográfica de Tomás F. Neve, México, p. 3. 
----- "Tampico" (1868) en Poesías, pp. 185-189.

----- : “Amar es vivir" [poema] (en Don Simón, Fresnillo, 17-1-1869, p. 3.

---- : “Dudas" [poemas] en Don Simón, Fresnillo, 21-2-1869, p. 3.

----- :Al tabaco" [poema] en EI Siglo XIX, 27-2-1870, pp. 2-3.

----- : “Almas gemelas” [poema] en El Domingo, México, 12-3-1871, p. 36.

----- : “Lágrimas" [poema] en El Domingo, México, 16-4-1871, pp. 83-84.

----- ; “Desencanto y consuelos” en El Domingo, México, 22-10-1871, p. 57.

"San Luis Potosi" (1861) en El Siglo XIX, 21-7-1861, p. 4.

SOSA, Francisco: "Emilio Rey" en El Siglo XIX, 5-9-1871, p. 3.

"Tampico" en La Sociedad, 10-5-1860, p. 3.

“Tepeji del Río" en La Unidad Católica, 23-12-1861, p. 2.

VIGIL, J. M.: “El año de 1871” en El Siglo XIX, 1-1-1871: p. 1.

\section{Bibliografía}

CRESPO LÓPEZ, M. (2004): Cántabros del siglo XIX. Semblanzas biográficas, Ediciones Librería Estudio, Santander, Biblioteca Cantabria.

GONZÁLEZ NAVARRO, M. (1993): Los extranjeros en México y los mexicanos en el extranjero 1821-1970, v. 1, El Colegio de México, passim.

MORA, P. y MIQUEL, A. (eds.) (2008): Españoles en el periodismo mexicano, siglos XIX y $x x$, UNAM, Instituto de Investigaciones Bibliográficas, Biblioteca Nacional, Hemeroteca Nacional / Universidad Autónoma del Estado de Morelos, passim. 